\title{
Pengaruh Variasi Jarak Penghalang Segitiga di Depan Silinder Arah Vertikal Terhadap Drag
}

\author{
( Putu Gede Gunawan Tista ${ }^{1)^{*}}$, I GNP Tenaya ${ }^{2)}$, I GN. Putu Sudanta ${ }^{3)}$ \\ ${ }^{1,2,3)}$ Jurusan Teknik Mesin Universitas Udayana, Kampus Bukit Jimbaran Bali
}

doi: 10.24843/JEM.2018.v11.i01.p03

\begin{abstract}
Abstrak
Salah satu cara untuk menghemat energi pada pesawat terbang dan bluff body lainnya adalah dengan mengurangi drag. Drag erat hubungannya dengan separasi aliran. Semakin awal terjadi separasi maka drag semakin meningkat. Oleh karena itu upaya yang dilakukan untuk mengurangi drag adalah dengan memanipulasi medan aliran fluida. Manipulasi aliran bisa dilakukan secara pasif antara lain menempelkan sebuah sirip pada bluff body, melubangi bluff body, menambahkan spiral pada bluff body dan menempatkan penghalang yang lebih kecil didepan bluff body. Penelitian ini yaitu dengan cara menempatkan penghalang berbentuk segitiga didepan silinder. Dalam penelitian ini pengujian dilakukan pada wind tunnel, yang terdiri dari blower, pipa pitot, manometer, pipa silinder, dan segitiga penghalang. Penempatan penghalang divariasikan pada arah vertikal posisi $y=0, y$ $=5 \mathrm{~mm}, y=10 \mathrm{~mm}, \mathrm{y}=15 \mathrm{~mm}$, sedangkan posisi penghalang pada arah horizontal pada jarak $60 \mathrm{~mm}$ terhadap silinder dengan panjang sisi segitiga adalah $8 \mathrm{~mm}$. Distribusi tekanan diperoleh dengan mengukur tekanan permukaan silinder pada 36 titik dengan interval $10^{\circ}$. Data yang diukur adalah tekanan permukaan silinder, tekanan statis, dan kecepatan aliran fluida. Hasil penelitian menunjukkan bahwa terjadi penurunan drag pada saat diberi penghalang segitiga dibandingkan dengan tanpa diberi penghalang segitiga. Nilai koefisien drag untuk silinder tanpa diberi penghalang yaitu 0.1276. Sedangkan dari variasi jarak penghalang pada arah vertikal diperoleh penurunan koefisien drag tertinggi adalah pada posisi $y=0$ yaitu sebesar 0,0186. Besarnya penurunan drag pada posisi ini adalah $85,45 \%$ dibandingkan dengan tanpa penghalang.
\end{abstract}

Kata kunci: Segitiga penghalang, separasi aliran , jarak penghalang, pengurangan drag

Abstract

One of the ways to reduce energy consumption an airplane and the other bluff body is by decreasing the drag. The drag is closely related to the flow of separation. The early separation, then the drag will increase. Based on the fact the effort to decrease drag is conducted by manipulating the field of fluid flow. The stream manipulation can be done passively, for example, by attaching a fin at the bluff body, by making a hole on the bluff body, enhancing spiral at the bluff body and placing a smaller barrier, on front of bluff body. The experiment was done by placing a triangle rod on front of the cylinder. In the present research the experiment was conducted in a wind tunnel, which consisted of a blower, a pitot pipe, a manometer, a main cylinder pipe, and a triangle rod. The triangle was variation vertical positioned at $y=0 \mathrm{~mm}, y=5 \mathrm{~mm}, y=10 \mathrm{~mm}, y=15 \mathrm{~mm}$. while the position of barrier in the horizontal direction at $60 \mathrm{~mm}$ distance towards the cylinder with the triangle side length was $8 \mathrm{~mm}$. Pressure distribution was measured on 36 points at the cylinder surface with an interval of $10^{\circ}$. The measured data was the pressure of cylinder surface, the static pressure, and the airflow speed. The research results showed that the triangle rod could decrease the drag of the main cylinder. The Coefficient drag for the cylinder without the triangle rod was 0,1276 while the variation of barrier in the vertical direction obtained the biggest decrease of the coefficient of the drag with the triangle rod happened at position $y=0$, which was 0,0186 . The magnitude of the drag reduction in this position was $85,45 \%$ compared without barrier.

Keywords: Triangle barrier, flow separation, barrier distance, drag reduction

\section{Pendahuluan}

Mekanika Fluida sangat berkaitan dengan dunia engineering. Penelitian terhadap fenomena aliran fluida yang melintasi suatu benda (bluff body) menjadi sangat penting karena memegang peranan seperti pada penukar kalor, pembakaran, dan alat transportasi. Apalagi dikaitkan dengan krisis energi yang melanda dunia dewasa ini.

Dalam dunia transportasi seperti pesawat udara, mobil, atau kapal laut, drag yang besar dihindari, karena energi atau tenaga yang dibutuhkan untuk bergerak menjadi besar. Sebagai contoh jika drag dari mobil dan bangunan dapat dikurangi maka banyak biaya bahan bakar dan material bisa dihemat [7].

Pola atau struktur aliran berbeda-beda tergantung geometri bluff body seperti silinder, segiempat, dan plat. Dalam aplikasi teknik, banyak sekali konstruksi yang menggunakan silinder. Aliran eksternal viscous yang mengalir melalui silinder akan mengalami stagnasi, lapisan batas, separasi (pemisahan) dan wake dibelakang silinder. Untuk benda yang bergerak dalam fluida viscous, gaya drag (gaya hambat) dan gaya lift (gaya angkat) erat hubungannya dengan separasi aliran [2].

Adanya separasi aliran akan menyebabkan timbulnya wake di belakang silinder yang mengakibatkan drag (hambatan). Semakin cepat terjadinya separasi aliran, wake akan semakin lebar sehingga drag semakin besar. Oleh karena itu, diperlukan penelitian tentang metode-metode pengontrolan fluida yang bertujuan untuk menunda separasi aliran external fluida viscous yang mengalir melalui silinder agar drag dapat diperkecil.

Salah satu cara yang dilakukan untuk mengurangi drag pada silinder adalah dengan metode 
pengontrolan pasif, yaitu dengan mengontrol aliran fluida. Pada penelitian ini akan dilakukan dengan menambah penghalang berbentuk segitiga di depan silinder yang berfungsi untuk memecah aliran fluida sehingga aliran yang mengenai silinder menjadi lebih turbulen. Momentum fluida dalam lapisan batas turbulen lebih besar daripada lapisan batas laminar, maka kemampuannya untuk melawan tegangan geser lebih besar sehingga akan lebih mampu untuk menunda terjadinya separasi.

Berbagai penelitian tentang drag yang mendukung penelitian ini antara lain:

Lee, et al. (2004), meneliti pengaruh pemasangan batang kontrol kecil pada upstream dari silinder dengan fokus pada karakteristik drag dan struktur aliran. Bilangan Reynold berdasarkan silinder utama $(\mathrm{D}=30 \mathrm{~mm})$ adalah sekitar $\quad \mathrm{Re}=20000$. Maksimum pengurangan koefisien total drag dari seluruh sistem meliputi silinder utama dan batang kontrol sekitar $25 \%$.

Tsutsui \& Igarashi (2002), mengkaji aliran sekitar silinder dengan menempatkan batang kecil pada upstream dari silinder. Diameter silinder adalah $D=40$ $\mathrm{mm}$, dan diameter batang d rentangnya dari 1 sampai $10 \mathrm{~mm}$.. Angka Reynold didasarkan pada $\mathrm{D}$ rentang dari $1,5 \times 10^{4}$ sampai $6,2 \times 10^{4}$. Pengurangan total drag yang meliputi drag dari batang adalah $63 \%$ dibandingkan dengan yang satu silinder.

Igarashi (1997), Mengkaji aliran sekitar Prisma segiempat dengan menempatkan batang kecil di depan prisma (upstream). Panjang sisi prisma $D$ adalah $30 \mathrm{~mm}$ dan bilangan Reynold Re adalah $3,2 \mathrm{x}$ $10^{4}$. Pada jarak kritis $G_{c}=D+4,5 d$, vortex dari batang hilang. Drag dari prisma menurun sekitar $50 \%$ pada $\mathrm{G}$ $>G_{c}$ dan $70 \%$ pada $G \leq G_{c}$.

Yajima \& Sano (1996), Mengkaji aliran sekitar silinder dengan melubangi sepanjang silinder dalam dua baris yang dibuat melintang diamater silinder. Pengurangan drag luar biasa didapat untuk bermacam-macam sudut serang. Besarnya pengurangan drag adalah $40 \%$ dibandingkan dengan silinder halus.

Bouk, at al. (1998), melakukan studi eksperimental menggunakan silinder kecil sebagai pengontrol pasif untuk mengurangi gaya drag pada silinder utama. Hasil eksperimental mereka menunjukkan bahwa ratarata penurunan gaya hambat maksimum sekitar $48 \%$ relatif terhadap silinder tunggal (tanpa pengontrol pasif).

\section{Dasar Teori}

Aliran inkompresibel melintasi silinder dapat dilihat pada gambar 1 .

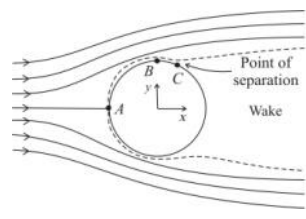

(a) Aliran Viscous

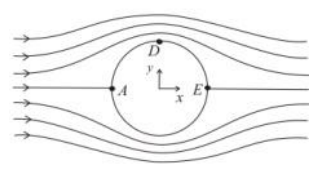

(b) Aliran inviscid
Gambar 1. Gambar Kualititatif aliran pada suatu silinder (Fox, 1985)
Pada Gambar1.a menunjukkan aliran viscous pada suatu silinder, streamlines adalah simetris. Titik $A$ adalah titik stagnasi dan selanjutnya terjadi boundary layer. Dari titik A ke titik B terjadi kenaikan kecepatan yang berakibat penurunan tekanan dan selanjutnya dari titik $B$ ke titik $C$ terjadi penurunan kecepatan yang berarti terjadi kenaikan tekanan $\mathrm{PC}>$ $\mathrm{PB}$. Di titik $\mathrm{C}$ momentum aliran tidak mampu melawan tegangan geser sehingga menyebabkan pecahnya boundary layer. Titik $\mathrm{C}$ disebut dengan point of separation. Di antara titik-titik atau tempat-tempat pemisahan boundary layer terjadi suatu kawasan yang disebut dengan wake. Makin besar wake makin besar terjadi perbedaan gaya di depan dan di belakang silinder berakibat makin besar gaya seret aliran terhadap silinder. Aliran inviscid digambarkan pada gambar 1.b. terlihat bahwa streamlines simetris, terjadi slip pada permukaan silinder dan perbedaan besar kecilnya kecepatan aliran ditunjukkan oleh rapat longgarnya streamlines yang ada dan juga tidak terjadi wake sehingga tidak terjadi gaya seret pada silinder.

Pengaruh turbulensi pada separasi aliran yang melintasi silinder dapat dilihat pada gambar 2 .

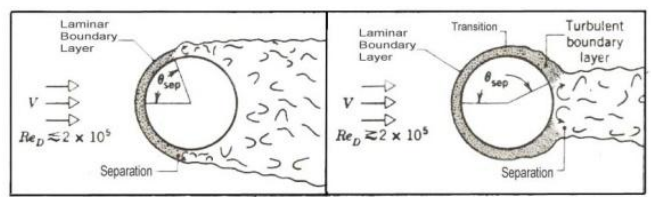

Gambar 2.Pengaruh turbulensi pada separasi (Incropera \& DeWitt, 1981).

Karena momentum fluida dalam lapisan batas turbulen lebih besar dari pada lapisan batas laminer, maka kemampuannya untuk melawan tegangan geser lebih besar sehingga akan lebih mampu untuk menunda yang menyebabkan separasi, itu layak untuk mengharapkan transisi. Jika $R_{\mathrm{D}} \leq 2 \times 10^{5}$, lapisan batas tetap laminer, dan separasi terjadi pada $\theta \approx 80^{\circ}$. Tetapi, jika $\operatorname{Re}_{\mathrm{D}} \geq 2 \times 10^{5}$, terjadi transisi lapisan batas, dan separasi ditunda sampai $\theta \approx 140^{\circ}$.

\section{Metode Penelitian}

Beberapa persamaan yang digunakan dalam perhitungan koefisien drag:

2.1. Rumus Koefisien Tekanan (Cp)

$$
C p=\frac{P-P o}{\frac{1}{2} \rho U o^{2}}
$$

Dengan:

$\mathrm{P}=$ Tekanan permukaan $\left(\mathrm{N} / \mathrm{m}^{2}\right)$

$\mathrm{Po}=$ Tekanan statik lingkungan $\left(\mathrm{N} / \mathrm{m}^{2}\right)$

$\mathrm{U} \mathrm{o}=$ Kecepatan aliran bebas $(\mathrm{m} / \mathrm{s})$

$\rho=$ Densitas fluida $\left(\mathrm{kg} / \mathrm{m}^{3}\right)$

2.2. Koefisien drag yang bekerja pada silinder diperoleh dengan mengintegralkan tekanan permukaan pada silinder (lee, et al., 2004) : 


$$
C_{D}=\int \frac{(P-P o) d A}{\frac{1}{2} \rho U o^{2} D L}
$$

\section{Dengan:}

$\mathrm{P} \quad=$ Tekanan permukaan silinder $\left(\mathrm{N} / \mathrm{m}^{2}\right)$

Po $=$ Tekanan statik lingkungan $\left(\mathrm{N} / \mathrm{m}^{2}\right)$

$\mathrm{L} \quad=$ Panjang silinder $(\mathrm{m})$

$\mathrm{D}=$ Diameter silinder $(\mathrm{m})$

Uo $=$ Kecepatan aliran bebas $(\mathrm{m} / \mathrm{s})$

$\rho=$ Densitas fluida $\left(\mathrm{kg} / \mathrm{m}^{3}\right.$

\subsection{Skema Instalasi Penelitian}

Peralatan yang digunakan dalam penelitian ini adalah : lorong udara (wind tunnel), pipa pitot, $U$ manometer, inclined manometer, silinder, segitiga penghalang, blower. Adapun skema instalasi penelitian adalah seperti pada gambar 1 .

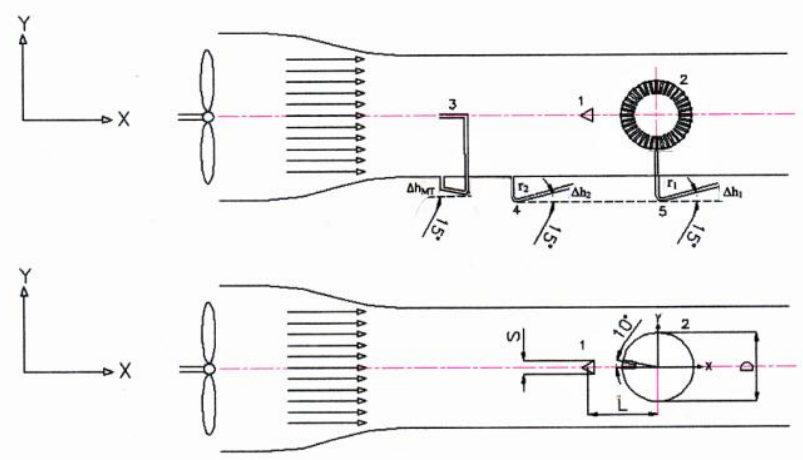

Gambar 3. Skema instalasi penelitian

Keterangan Gambar 3.1. :

1. Penghalang berbentuk segitiga

2. Silinder

3. Pitot pengukur tekanan total

4. Manometer tekanan statis

5. Manometer tekanan permukaan silinder

$\mathrm{L}=$ Jarak segitiga penghalang dengan silinder

$\mathrm{D}=$ Diameter silinder

$\mathrm{S}=$ Sisi segitiga penghalang

\section{Cara Kerja dan Teknik Pengambilan data}

Aliran udara yang dihembuskan oleh blower mengalir dalam wind tunnel dan melintasi penghalang berbentuk segitiga sama sisi dan mengenai silinder. Silinder yang digunakan pipa PVC jenis AW, Permukaan silinder dilubangi sebanyak 36 lubang dengan diameter $1 \mathrm{~mm}$, dan dihubungkan dengan selang berdiameter $2 \mathrm{~mm}$ ke inclined manometer. Pemasangan pressure tube dilakukan pada keliling silinder pada bagian tengah. Posisi tiap titik dari pressure tube berjarak $10^{\circ}$ dari titik pusat, sehingga akan diperoleh 36 titik pressure tube pada silinder.

Untuk mengukur tekanan permukaan (P) (alat ukur 5), pembacaan manometer dilakukan secara manual. Kecepatan aliran udara wind tunnel diukur dengan pipa pitot (3) yang membaca tekanan total, sedangkan alat ukur (4) yang dihubungkan dengan selang berdiameter $2 \mathrm{~mm}$ untuk mengukur tekanan statis (Po) yang juga dibaca secara manual.
Kecepatan udara bebas Uo diproses dari tekanan dinamik yakni selisih antara tekanan total dan tekanan statik.

\section{Prosedur Pengambilan Data}

Prosedur pengambilan data dilaksanakan setelah menentukan atau mengatur semua instrumen yang mendukung dalam proses pengambilan data.

Langkah-langkah yang diambil antara lain :

1. Meletakkan silinder dan segitiga penghalang di dalam wind tunnel di depan dari saluran subsonik.

2. Menghidupkan blower

3. Setelah blower berjalan stasioner dilakukan pengambilan data

4. Pengambilan data distribusi tekanan dengan variasi jarak kea rah vertikal, dilakukan dengan mengambil data pada permukaan silinder.

5. Pengambilan data dilakukan sebanyak tiga kali pada setiap posisi pengujian baik tanpa penghalang maupun dengan penghalang segitiga. Dilakukan juga pengambilan data untuk kecepatan aliran bebas di depan dari saluran subsonik dan juga pengukuran tekanan statik.

\section{Hasil dan Pembahasan}

Hasil penelitian pada silinder dengan ring penampang bulat dan segi empat, kecepatan aliran udara $U_{0}=8,8 \mathrm{~m} / \mathrm{s}$, dengan bilangan Reynolds $\mathrm{Re}=3.64 \times 10^{4}$ adalah seperti terlihat pada gambar berikut.

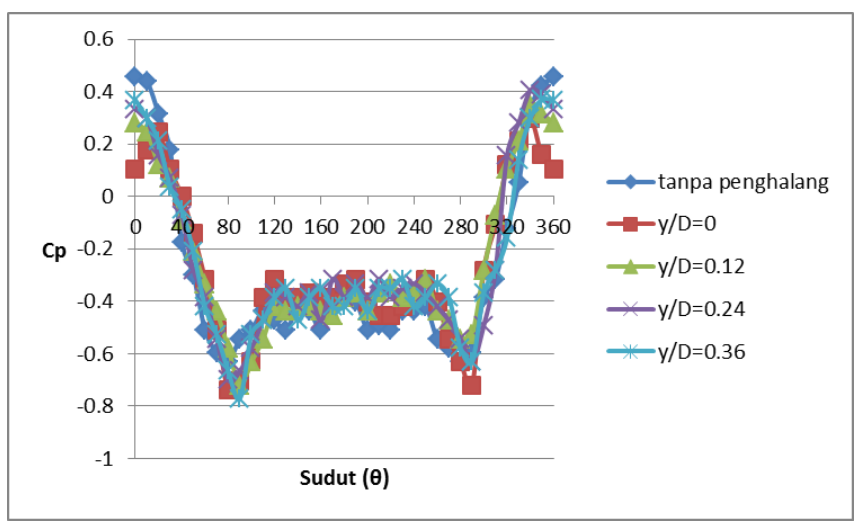

Gambar 4. Grafik hubungan koefisien tekanan (Cp) terhadap sudut $(\theta)$.

Pada gambar 4. Menunjukkan grafik hubungan koefisien tekanan $(\mathrm{Cp})$ terhadap sudut silinder $(\theta)$, tanpa penghalang dan dengan penghalang segitiga yang jaraknya divariasikan pada arah vertikal yaitu pada $y / D=0,0.12,0.24$ dan 0.36 . Penurunan tekanan yang terjadi sangat tajam yang menunjukkan terjadi peningkatan kecepatan aliran setelah mengenai penghalang segitiga. Titik stagnasi tidak selalu pada sumbu silinder tapi berubah sesuai dengan variasi jarak ke arah vertikal. Titik separasi berubah sesuai dengan jarak penghalang kea rah vertikal. Titik separasi pada tanpa penghalang segitiga adalah $110^{\circ}$ sedangkan dengan penghalang berubah menjadi $120^{\circ}$. Perubahan titik separasi ini disebabkan oleh aliran yang setelah mengenai penghalang segitiga 
terjadi percepatan aliran yang meningkatkan momentum aliran untuk mengatasi gesekan pada permukaan silinder.

Untuk grafik hubungan koefisien drag terhadap jarak kea rah vertikal ditunjukkan pada gambar 5 .

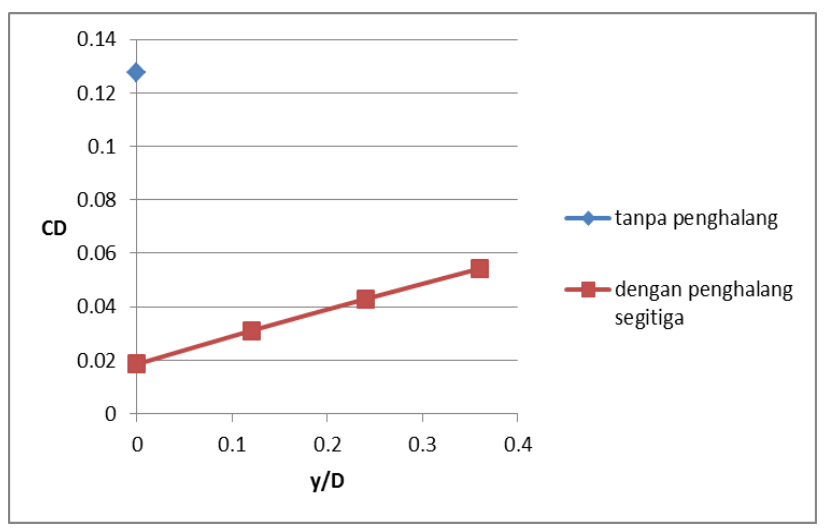

Gambar 5. Grafik hubungan koefisien drag (CD) terhadap jarak vertikal y/D.

Pada gambar 5. Menunjukkan hubungan koefisien drag (CD) terhadap perbandingan jarak vertikal dengan diameter silinder $(y / D)$ dengan penghalang dan tanpa penghalang segitiga. Terlihat bahwa terjadi penurunan drag dibandingkan tanpa penghalang. Semakin besar jarak vertikal dari sumbu silinder koefisien drag semakin besar. Hal ini disebabkan pada jarak vertikal yang semakin jauh dari sumbu silinder terjadi ketidakseimbangan aliran yang diterima silinder, dimana pada salah satu bagian terjadi kehilangan energi kinetik yang cukup besar. Oleh karena itu, momentum aliran tidak mampu mengatasi gesekan yang terjadi, sehingga separasi aliran terjadi di awal dan wake dibelakang silinder menjadi besar yang menyebabkan beda tekanan di depan dan di belakang silinder menjadi besar. Selanjutnya perbedaan tekanan di depan dan dibelakang silinder yang besar ini menyebabkan drag besar. Penurunan koefisien drag terbesar terjadi jarak vertikal $y / D=0$ yaitu besarnya $C D=0.01856$. Besarnya penurunan koefisien drag dibandingkan dengan tanpa penghalang segitiga adalah $85.45 \%$.

\section{Simpulan}

Dari hasil penelitian yang telah dilakukan dapat ditarik kesimpulan sebagai berikut:

1. Adanya penghalang segitiga mampu menurunkan koefisien drag

2. Semakin jauh jarak penghalang segitiga pada arah vertikal dari sumbu silinder semakin besar koefisien dragnya.

\section{Ucapan Terima Kasih}

Terima kasih kepada Program Studi Teknik Mesin Universitas Udayana yang telah menyediakan tempat dan fasilitas untuk melakukan penelitian.

\section{Daftar Pustaka}

[1] Bouak, F, and Lemay, J, Passive Control of the Aerodynamics Forces Acting on a Circular Cylinder, ExperimentalThermal and Fluid Science, 16, pp. 112-121,1998.

[2] Chew, $Y$ T., L $S$ Pan, \& $T S$ Lee, NumericalSimulation Of The Effect Of a Moving Wall On Separation Of Flow Past a Symmetrical Aerofoil, ImechE, 212.1997.

[3] Fox, R. W., Introduction To Fluid Mechanics, John Wiley \& Sons, New York, 1985.

[4] Igarashi, T., Drag Reduction Of a Square Prism by Flow Control Using a Small Rod, Journal of Wind Engineering and Industrial Aerodynamics, $69-71,141-153,1997$.

[5] Incropera, F. P. \& D. P. DeWitt. 1981. Fundamentals Of Heat And Mass Transfer, John Wiley \& Sons, New York, 1981.

[6] Lee, S., S. Lee, \& C. Park, Reducing The Drag On a Circular Cylinder by Upstream Installation Of a Small Control Rod, Fluid Dynamics Research , 34: 233-250, 2004.

[7] Tsutsui, T. \& T. Igarashi, Drag Reduction of a Circular Cylinder in an Air-Stream, Journal of Wind Engineering and Industrial Aerodynamics, 90(2002): 527-541.

[8] Yajima, Y \& O. Sano, A Note On The Drag Reduction Of a Circular Cylinder Due To Double Rows Of Holes, Fluid Dynamics Research, 18(1996): 237 - 243. 1996.

\begin{tabular}{|l|l|} 
Si Putu Gede Gunawan Tista \\
menyelesaikan studi S1 di \\
Universitas Udayana, pada \\
tahun 1994, kemudian \\
menyelesaikan \\
magister teknik di Jurusan \\
Teknik Mesin Universitas \\
Brawijaya pada tahun 2006. \\
Bidang penelitian yang diminati \\
adalah tentang pengurangan \\
drag.
\end{tabular}

